\title{
Infant feeding intentions of new mothers in five European countries
}

\author{
H. Gage ${ }^{1}$, J. Morgan ${ }^{1}$, P. Williams ${ }^{1}$, M. Schmid ${ }^{1}$, K. Laitenen ${ }^{2}$, J. von Rosen ${ }^{3}$, B. Koletzko ${ }^{3}$, T. Decsi ${ }^{4}$, \\ V. Jacobi ${ }^{4}$, E. Martin-Bautista ${ }^{5}$, C. Campoy $^{5}$ and M. M. Raats ${ }^{1}$ \\ ${ }^{1}$ Food, Consumer Behaviour and Health Research Group, University of Surrey, Guildford GU2 7XH, UK, ${ }^{2}$ Department \\ of Biochemistry and Food Chemistry, University of Turku, Turku, Finland, ${ }^{3} \mathrm{Dr}$ von Hauner Children's Hospital, \\ Munich, Germany, ${ }^{4}$ Department of Pediatrics, University of Pecs, Pecs, Hungary and ${ }^{5}$ Department of Pediatrics, \\ University of Granada, Granada, Spain
}

Primiparvus mothers with healthy singleton babies in England, Finland, Germany, Hungary and Spain were asked about their milk feeding and weaning intentions in 2005. Following informed consent, questionnaires were completed by mothers shortly after the birth of their baby, and included items asking about their socio-demographic characteristics, sources of information on infant feeding, and beliefs about the effect of early nutrition on the immediate and future health of the child. Mothers were recruited through the maternity services in the locality of the researchers.

A total of 2071 mothers completed questionnaires (England, 438; Finland, 426; Germany, 414; Hungary, 389; Spain, 404). The mean age of mothers was 30.0 (SD 0.02) years, ranging from 28.1 (SD 4.03) in Hungary to 32.1 (SD 4.95) in Germany (ANOVA; $P<0.001$ ). The percentage of mothers who had undertaken further or higher education (post 18 years) varied between countries (England, 89.9; Finland, 59.6; Germany, 75.6; Hungary, 48.8; Spain, 26.3; $\chi^{2}, P<0.001$ ). Significant differences also existed between countries in mothers' stated intentions in relation to milk feeding (Table 1) and weaning time (Table 2).

Table 1. Stated milk feeding intentions of new mothers from five European countries

\begin{tabular}{|c|c|c|c|c|c|c|c|c|c|c|c|c|}
\hline & \multicolumn{2}{|c|}{ England } & \multicolumn{2}{|c|}{ Finland } & \multicolumn{2}{|c|}{ Germany } & \multicolumn{2}{|c|}{ Hungary } & \multicolumn{2}{|c|}{ Spain } & \multicolumn{2}{|c|}{ All } \\
\hline & $n$ & $\%$ & $n$ & $\%$ & $n$ & $\%$ & $n$ & $\%$ & $n$ & $\%$ & $n$ & $\%$ \\
\hline Breast-feed & 297 & 68.0 & 297 & 69.7 & 378 & 97.2 & 369 & 89.1 & 354 & 87.6 & 1695 & 81.9 \\
\hline Breast- and bottle feed & 108 & 24.7 & 125 & 29.3 & 9 & 2.3 & 26 & 6.3 & 33 & 8.2 & 301 & 14.5 \\
\hline Bottle (formula) feed & 30 & 6.9 & 0 & 0 & 0 & 0 & 18 & 4.3 & 15 & 3.7 & 63 & 3.0 \\
\hline Don't know & 2 & 0.5 & 4 & 0.9 & 2 & 0.5 & 1 & 0.2 & 2 & 0.5 & 11 & 0.5 \\
\hline Total & 437 & 100 & 426 & 100 & 389 & 100 & 414 & 100 & 404 & 100 & 2070 & 100 \\
\hline
\end{tabular}

$\chi^{2} 250.15$, df $12, P<0.001$.

Table 2. Stated weaning intentions of new mothers from five European countries

\begin{tabular}{|c|c|c|c|c|c|c|c|c|c|c|c|c|}
\hline & \multicolumn{2}{|c|}{ England } & \multicolumn{2}{|c|}{ Finland } & \multicolumn{2}{|c|}{ Germany } & \multicolumn{2}{|c|}{ Hungary } & \multicolumn{2}{|c|}{ Spain } & \multicolumn{2}{|c|}{ All } \\
\hline & $n$ & $\%$ & $n$ & $\%$ & $n$ & $\%$ & $n$ & $\%$ & $n$ & $\%$ & $n$ & $\%$ \\
\hline Before 4 months & 14 & 3.5 & 13 & 3.2 & 10 & 2.6 & 10 & 2.6 & 18 & 8.1 & 65 & 3.6 \\
\hline 4-5.99 months & 104 & 25.7 & 185 & 45.5 & 46 & 12.4 & 51 & 13.2 & 84 & 37.7 & 470 & 26.2 \\
\hline 6 months or later & 287 & 70.9 & 209 & 51.4 & 316 & 84.9 & 325 & 84.2 & 121 & 54.3 & 1258 & 70.2 \\
\hline Total & 405 & 100 & 407 & 100 & 372 & 100 & 386 & 100 & 223 & 100 & 1793 & 100 \\
\hline
\end{tabular}

$\chi^{2} 163.12$, df $4, P<0.001$.

Health factors, rather than convenience or cost, were cited as a reason for intending to exclusively breast-feed most frequently in England (about one-third of stated reasons) and least often in Spain (approximately one-eighth). Personal sources of information (friends and family) were more important influences on infant feeding decisions than medical sources (doctors, nurses, midwives) in England and Germany, but healthcare professionals were more important to mothers in Finland, Hungary and Spain.

This study was supported as a part of the European Project 'Early Nutrition Programming-EARNEST' within the 6th Framework Programme; no. FOODCT-2005-007036. 